\title{
SOSIALISASI BERMEDIA SOSIAL YANG HUMANIS BAGI GURU DAN ORANG TUA SISWA
}

\author{
Hendri, Moh. Khoiri, Herdi Wisman Jaya, \& Imas Masriah \\ Universita Pamulang \\ Email : dosen02650@unpam.ac.id
}

\begin{abstract}
Abstrak
Media social (social media) saat ini menjadi kebutuhan pokok masyarat. Hampir semua lapisan masyarakat menggunakan social media untuk mengakses segala sesuatunya. Dengan social media segala informasi dapat diakses dengan mudah cepat. Dan sinilah masyakat mulai memanfaatkan perkembangan media digital ini sebagain alat intraksi komunikasi social dengan yang lainnya: berbagi ilmu pengetahuan, lewat tulisan, gambar, video dan lainnya melalui media social berbasis digital. Media social seperti candu bagi kehidupan masyarakat, bahkan karenanya tidak segan-segang masyarakat untuk mengeluarkan biaya besar. Ini yang harus menjadi sorotan kita bersama, bahwa ketergantungan masyarakat pada media social memberikan berbagai macam dampak: positif dan juga negative. Dampak positif, artinya masyarakat dapat dengan baik menggunakan social media. Sedangkan dampak negatif adalah kecenderungan masyarakat hanya mampu menggunakan saja, tanpa memahami fungsi dari tujuan yang sebenarnya, dan hasilnya pun dapat merugikan orang lain, terlebih dirinya sendiri. Hal ini yang dirasa perlu oleh kita (tiem PkM) untuk disosialisasikan bagaimana bersosial media yang humanis bagi masyarakat, orang tua siswa termasuk guru-guru SMPN 9 Tangerang Selatan. Melalui sosialisasi ini akan ada banyak trik dan tip dalam menghadapi masalah yang sering ditemukan dilingkungan dalam komunikasi kehidupan sosial guru dan orang tua di sekolah salah satunya dengan kebijakan sekolah.
\end{abstract}

Kata kunci: Media, Sosial, Humanis

\begin{abstract}
Social media (social media) is currently a basic need of society. Almost all levels of society use social media to access everything. With social media all information can be accessed easily and quickly. And this is where the community begins to take advantage of the development of digital media as a means of social communication interaction with others: sharing knowledge, through writing, pictures, videos and others through digital-based social media. Social media is like an opium for people's lives, and because of that, people don't hesitate to spend big money. This should be our common spotlight, that people's dependence on social media has various impacts: positive and negative. Positive impact, meaning that people can use social media well. While the negative impact is the tendency of people to only be able to use it, without understanding the function of its true purpose, and the results can be detrimental to others, especially themselves. This is what we (the PkM team) feel is necessary to socialize on how to socialize humane media for the community, parents of students, including the teachers of SMPN 9 South Tangerang. Through this socialization, there will be many tricks and tips in dealing with problems that are often found in the environment in the communication of the social life of teachers and parents at school, one of which is school policy.
\end{abstract}

Keywords: Media, Social, Humanist

\section{PENDAHULUAN}

Kemajuan teknologi menjadi sarana dan prasarana mobilitas sosial masyarakat dalam memenuhi kebutuhan sehari-hari. Tidak dapat dipungkiri kemajuan teknologi sangat berdampak besar bagi kehidupan masyarakat, mulai dari kehidupan masyarakat menengah keatas hingga kebawah yaitu membantu mempermudah memberikan fasilitas akses. Hampir semua kebutuhan masyarakat terbantukan oleh kamajuan teknologi, baik berkaitan dengan 
jasa, kesehatan, bisnis, terlebih pendidikan. Singkatnya, teknologi merupakan sarana komunikasi sosial masyarakat dalam mengakses segala seuatu yang dibutuhkan. Mungkin ini lah yang melatarbelakangi peralihan media komunikasi masyarakat yang sifatnya konvensional menjadi lebih modern, atau disebut sebagai "komunikasi berbasis teknologi digital".

Media komunikasi semakin meningkat hebat, apalagi saat akses jejaring internet mulai menjembatani teknologi, seperti leptop, telepone seluler yang dapat menghubungkan jejaring komunikasi dunia semakin mudah, yang jauh dapat dijangkau dengan mudah sebab akses internet. Bahkan saat ini pegiat teknologi komunikasi selalu melakukan inovasi terhadap alat komunikasi, telepone seluler biasa menjadi telepone cerdas (smartphone) yang sudah dilengkapi dengan berbagai aplikasi komunikasi, seperti WhatsApp, Facebook, Instagram, Twitter, Selegram, Michat, Zoom, Google Meet dan masih banyak lainnya. Jadi jika dilihat dari manfaatnya, teknologi itu dapat diartikan sebagai alat yang membantu memecahkan permasalahan manusia, meringankan dan mempermudah manusia dalam segala aksesnya (Andri, R. M., \& SP, M. P. 2017).

Mengutip dari pendapatan Nasrullah (2015) bahwa media social yang merupakan perkembangan dari teknologi, saat ini marak digunakan oleh lapisan masyarakat: pejabat, guru, orang tua dan siswa merupakan hasil dari akses internet yang memungkinkan masyarakat dengan mudah dapat melihat segala bentuk yang diinginkan. Akses internet ini juga membuka akses komunikasi yang tak terbatas, baik dengan masyarakat yang dekat mau pun yang jauh dari jangkauan lokasi kita sehingga masyarakat dengan mudah dapat bertukar informasi antar sesama. Nah, dalam pengaplikasian media sosial ini setidaknya kita mengenal tiga bentuk yang merujuk pada pemaknaannya, yaitu pengenalan (cognition), komukasi (communicate) dan kerjasama (coorporation).

Masyarakat dalam menggunakan aplikasi media komunikasi semakin hari semakin meningkat, hingga banyak kalangan programer yang berlomba-lomba menawarkan aplikasi baru dengan fasilitas lengkap pada masyarakat (pengguna). Hal ini dapat kita lihat dari hasil riset We Are Social dalam penelitiannya mengungkapkan bahwa kapasitas pengguna internet dan media social di Indonesia cukup tinggi dengan persentase 15 persen angka penetrasi internet atau sekitar 38 juta orang dari total 62 juta orang pengguna internet jika dilihat dari akun yang terdaftar di media sosial Facebook. Nah, dari hasil riset tersebut juga menyatakan bahwa rata-rata masyarakat Indonesia menghabiskan waktu hampir 3 jam untuk berselancar di media sosial dengan menggunakan internet (Setiadi, A. 2016). Tapi dari besaran pengguna tersebut sedikit masyarakat yang menggunkan dengan baik dan bijak.

Hal diatas diperkuat dengan hasil analisis Zifana dalam (Ali Kusno, 2015) bahwa sepanjang tahun 2013, direktori pencarian pada situs Mahkamah Agung RI mencatat ada 791 kasus pencemaran nama baik di seluruh Indonesia yang telah diputuskan di berbagai tingkat pengadilan, mulai dari Pengadilan Negeri hingga 
Mahkamah Agung. Kemudahaan dan kebebasan orang dalam menggunakan media sosial seperti Facebook, Twitter, Instagram, Path, BBM, whatsApp dan lainya menjadi pemicu banyaknya kasus penghinaan dan pencemaran nama baik (Nurgiansah, 2021). Selain itu, rendahnya kesadaran masyarakat dalam menggunakan bahasa yang sopan di media sosial menjadi faktor pendorong terjadinya disintegrasi komunikasi social digital yang baik.

$$
\text { Mengadopsi dari pendapat }
$$

Zainuddin, M., \& Agustang, A. (2019) bahwa yang terjadi pada kalangan remaja dalam memanfatakan media social adalah berlebihan dalam penggunaan media social yang berbentuk Game dan sifatnya menghibur, misalnya COC (Clash of Clan) ML (Mobile legends), PUBG atau aplikasi lainya seperti Tiktok yang membuat remaja lupa waktu. Mungkin sebab permasalahan diatas tersebut hingga di SMPN 9 Tangerang Selatan mengambil kebijakan bahwa siswa tidak boleh membawa HP ke sekolah.

Kebijakan tersebut merupakan salah satu upaya dalam memutus matarantai permasalahan atau kekuatiran yang akan terjadi manakala siswa SMPN 9 Tangerang Selatan diberikan keleluasaan menggunakan HP di sekolah. Mungkin hal tersebut sah-sah saja dilakukan oleh sekolah dimana pun termasuk di SMPN 9 Tangerang Selatan dalam rangka mengefektifkan konsentrasi belajar siswa dengam baik. Namun, disisi lain hal ini juga dikatagorikan sebagai salah satu bentuk masalah baru sebab kebijakan tersebut merupakan salah satu pengkerdilan dengan penyempitan akses akslarasi pengetahuan dan informasi pada siswa dengan mudah lewat internet, youtube atau media social lainya, serta terputusnya komunikasi antar anak dengan orang tua di sekolah, dengan kejibakan ini pula akan menimbulkan kehawatiran bagi orang tua dalam suatu waktu manakala ada agenda yang membuat siswa tidak tepat waktu pulang sekolah tanpa ada informasi (Nurgiansah, 2020).

Kehawatiran sudah tentu terjadi
atau ada pada setiap guru dalam
keleluasaan akses media di HP dalam waktu pembelajaran, namun dengan adanya ini jangan sampai membuat dan mempersempit siswa dalam mengexplorasi pengetahuan serta kreasi siswa di luar sekolah mau pun didalam sekolah melalui pengaplikasian media social digital sebagai alat komunikasi (Dewantara \& Nurgiansah, 2021b). Kebijakan tersebut menunjukkan bahwa ada disintegrasi komunikasi antara guru dan siswa yang mengakibatkan sekolah harus memberikan kebijakan tidak boleh membawa HP, padahal manfatnya HP juga banyak, selain sebagai alat komunikasi bermanfaatnya juga untuk mengakses media pembelajaran, misalnya quizizz, youtube dan lain sebagainya, tentu aktivitas ini dilakukan dalam pengawasan guru (Rachman et al., 2021).

Mari kita lihat dari hasil penelitian yang dilakukan oleh Rosyadi, I. (2018) dengan judul penelitian "Pengaruh Multimedia Presentasi Terhadap Kemampuan Menulis Teks Eksplanasi Pada Siswa Kelas VIII SMPN 9 Tangerang Selatan". Hasil akhir yang diperoleh dalam penelitian tersebut adalah penggunaan multimedia presentasi berpengaruh terhadap kemampuan menulis teks 
eksplanasi siswa. Hasil tersebut diperoleh karena pilihan media yang tepat sesuai dengan sasarannya. Contoh lain dari hasil penelitia yang dilakukan pada Sekolah yang sama yaitu SMPN 9 Tangerang Selatan, Puspita, I. (2017) Tentang "Efektivitas Penggunaan Media Video Animasi dalam Proses Pembelajaran Pendidikan Agama Islam Kelas VIII-1 di SMPN 9 Tangerang selatan" dari penelitian ini menjelaskan bahwa pembelajaran yang menggunakan media social berbentuk video lebih menarik dan tidak membosankan. Hasil tersebut sangat jelas kemanfaatan media social digital dalam pembelajaran. Padahal di SMPN 9 Tangerang Selatan tidak diperkanankan siswa membawa HP. Dari sini dapat disimpulkan bahwa siswa dengan keterbatasan akses lewat HP pun dapat berprestasi apalagi sekolah memberikan leluasa pada siswa untuk mengfungsikan media sosioal lewat HP masing-masin.

Dari argumentasi diatas dapat diartikan bahwa membangun komunikasi yang humanis di media sosila bukan berarti masyarakat dan bahkan anak didik kita tidak diperbolehkan untuk mendapatkan fasilitasnya, akan tetapi bagiamana cara kita memberikan kesadaaran kepada mereka (kita: anak didi, guru dan orang tua) untuk dapat menggunakan media social pada tempat yang benar dan bermanfaat bagi kita dan orang lain. Memberikan batasan-batasan boleh saja dengan kebijakan yang mengikat tapi jangan sampai merampas hak mereka dalam mengembagkan kreatifitasnya lewat social media, sebab komunikasi yang humanis adalah komunikasi yang tidak mencederai siapa pun dalam bentuk apa pun. Oleh karena itu perlunya penyuluhan tentang bagaimana masyarakat, lembaga pendidikan, khususnya SMPN 9 Tangerang Selatan dalam membangun komunikasi social media yang baik dan humanis.

Penyuluhan ini adalah salah satu usaha sadar dalam menyusun, merancang serta mencerdasakan masyarakat dalam melatih kepekaan pada setiap kondisi dan situasi, serta keakuratan data yang ingin disampaikan sebagai bahan komunikasi. Upaya membangun keharmonisan komunikasi digital yang disebabkan keterbatasan kemampuan, harus direspon dengan baik, sebab dengan kedangkalan pengetahuan tersebut dapat mengakibatkan fatal. Misalnya, dalam setiap informasi dalam sebuah media, termasuk media sosial memiliki hak cipta yang diatur dalam UU NO 19 Tahun 2002 tentang Hak Cipta. Pasal tersebut menjadi dasar hukum etika dalam penggunaan media komunikasi di Indonesia dan UU ITE yang mengatur tentang informasi serta transaksi elektronik, atau teknologi informasi, jika masyarakat tidak hati-hati dan memahaminya akan terjerat sebagai merebut hak orang lain.

Berdasarkan latarbelakang itulah kami (Tiem PkM Program Studi Pendidikan Pancasila dan Kewarganegaraan) hadir, ikut berpartisipasi membatu permasalahan yang ada disekolah lewat pengabdian kami yang bertema "Sosialisasi Bersosial Media yang Humanis Antara Guru dan Orang Tua Siswa di SMP Negeri 9 Tangerang Selatan.

\section{METODE PENELITIAN}

Metode yang digunakan dalam pengabdian masyarakat ini adalah melalui metode pembelajaran atau penyuluhan 
memberikan pendidikan (edukasi), mensosialisasikan social media yang humanis kepada guru atau para pendidik melalui virtual. Kegiatan ini dilakukan secara virtual melihat kondisi dan situasi saat ini memang belum pulih dari bahaya Covid 19. Sedanghkan kegiatan ini menetapkan target audiens adalah guru dan tenaga pendidikan SMPN 9 Tangerang Selatan.

Dalam melaksanakan kegiatan PkM itu, terlebih dahulu dilakukan pengamatan (observasi) dan wawancara kepada pihak sekolah terkait dengan kebutuhan mitra atau permasalahan yang dibutuhkan bantuan dari akademisi. Melaui observasi awal tersebut kemudia ditemukan titik dasar permasalahan yang ada di SMPN 9 Tangerang Selatan. Kemudian dikembangkan menjadi pokok pembahasan dalam aktivitas selanjutnya.

Dibentuk rumusan masalahan dari latarbelakang yang universial menjadi lebih mengkrucup pada aspek permasalahan pokok di SMPN 9 Tangerang Selatan, sehingga dari permasalahan tersebut muncul paradigma bahwa SMPN 9 Tangerang Selatan membutuhkan sosialisasi bermedia social yang humanis antara guru dan orang tua siswa, mengingat media social yang berbasis digital saat ini mulai berkembang pesat dengan berbagai macam fitur yang menarik.

\section{HASIL PENELITIAN DAN PEMBAHASAN Hasil Penelitian}

Hasil penelitian yang diperoleh melalui proses observasi, dokumentasi dan wawancara adalah menunjukkan perlunya penyuluhan, pengayaan dan pendampingan (sosialisasi) pada guru serta orang tua siswa untuk memperoleh pengetahuan pentingnya menggunakan media sosial berbasis digital sebagai alat menjalin komunikasi yang baik dan Humanis di lingkunga sekolah dan bahkan diluar. Hal ini disebabkan karena masih banyak disintegrasi komonikasi humanis dalam memanfaatkan media social digital.

\section{Pembahasan}

Teknologi merupakan hasil olah pikir kemampuan manusia yang dikembangkan dari masa ke masa, mulai dari hanya berbentuk mesin uap hingga saat ini, yang kemajuan dan perkembangannya hampir mewakili dan menggantikan aktivitas manusia (Dewantara \& Nurgiansah, 2021a). Misalnya, alat transportasi: mobil, motor, kapal laut, dan pesawat terbang. Alat komunikasi, seperti handphone, smartphone canggih yang didalamnya sudah dilengkapi dengan berbagai macam fitur dan aplikasi.

Suatu hal yang mustahil manakala masyarakat ingin memutus, tidak menggunakan atau menolak perkembangan kemajuan perkembangan teknologi komunikasi lewat social media. Sebab dimana manusia masih berpikir kreatif maka disitulah teknologi akan selalu berinovasi. Hal ini didukung oleh pernyataan Alinurudin bahwa kemajuan teknologi menjadi hal yang penting khususnya saat ini (pandemi) bagi perkembagan pendidikan dan pengajaran, yang awalnya pembelajaran dilakukan dalam ruangan saat ini dapat diakses lewat media social ${ }^{1}$.

1 Disampaikan pada saat menjadi sambutan pelaksanaan Pengabdian kepada Masyarakat (PkM) tanggal 26 September 2021, virtual. 
Syahputra, A. K., Kurniawan, E., \& Nofriadi, N. (2019) berpendapat bahwa social media yang dibangun dengan tujuan yang baik akan menghasilkan dampak yang baik, sebaliknya jika digunakan dengan tujuan yang kurang baik maka akan merugikan banyak orang. Sebab kemudahan akses imformasi lewat media social menjadi pelayanan kilat dalam mentrasfer informasi tanpa batas oleh siapa saja, khususnya yang dimaksud oleh pelakunya dan dengan percepatan ini lah segala tujuan akan sangat mudah dicapai. Oleh karena itu sosial media tidak dapat dipisahkan dari kebutuhan masyarakat dalam mencapai tujuan lewat penyampaian informasi atau menerima informasi social media.

Penggunaan sosial media yang dikembangkan melalui perkembangan teknologi saat ini (smartphone) bukan hal yang tabu dalam kehidupan masyarakat, akan tetapi keberadaan dan perkembangan alat ini sebagai alat komunikasi, menyampaikan informasi dan menerima informasi adalah menjadi hal yang paling pokok dalam kehidupan masyarakat saat ini, khususnya guru sekolah SMPN 9 Tangerang selatan dalam membangun komunikasi aktif dengan orang tua siswa dan siswa itu sendiri. Dalam menggunakan kemajuan media sosial digital ini menurut pendapat Imas Masriah adalah bagaimana masyarakat paham fungsi dan tujuannya, serta masyarakat mengetahui dampak yang akan diperoleh dalam menggunakan media sosial digital tersebut sehingga dalam penggunaannya masyarakat: guru, orang tua siswa dan siswa harus mampu menggunakan dengan bijak dan humanis ${ }^{2}$.

Menurut Khoiri dampak positif dari media sosial adalah memudahkan kita untuk berinteraksi dengan banyak orang, memperluas pergaulan, jarak dan waktu bukan lagi masalah, lebih mudah dalam mengekspresikan diri, penyebaran informasi dapat berlangsung secara cepat, biaya lebih murah dan meningkatkan kreasi anak didik yang tidak terbatas ${ }^{3}$.

Sedangkan dampak negatif dari media sosial adalah menjauhkan orangorang yang sudah dekat dan sebaliknya, interaksi secara tatap muka cenderung menurun, membuat orang-orang menjadi kecanduan terhadap internet, menimbulkan konflik, masalah privasi, rentan terhadap pengaruh buruk orang lain. Misalnya yang kita lihat akhir-akhir ini terjadi seperti maraknya kejahatan di sosial media, informasi bohong/hoax, menurunkan produktivitas, membuat seseorang menjadi individualis, membuat kualitas tidur menurun, membuat depresi dan kecemasan, kecanduan hingga lupa waktu. Itu disebabkan karena tidak ada pengetahuan tentang tujuan dan bagiamana cara menggunakan sosial media dengan biak (Fitriani, Y. 2017).

Oleh karenanya harus ada upayaupaya dalam mencegah hal negatif yang dapat merugikan orang lain dan juga diri sendiri diantaranya dengan jangan asal posting konten, protect your privacy, jaga

2 Disampaikan pada saat menjadi narasumber dalam pelaksanaan Pengabdian kepada Masyarakat (PkM) tanggal 26 September 2021, virtual

3 Disampaikan pada saat menjadi narasumber dalam pelaksanaan Pengabdian kepada Masyarakat (PkM) tanggal 26 September 2021, virtual 
etika, selalu waspada dan jangan langsung percaya dan filter akun-akun yang diikuti. Lebih rincinya dapat dilihat rekomendasi dari Khori sebagai bentuk antisipasi dalam membangun gaya bersosial media yang humanis bagi guru dan orang tua siswa, yaitu sebagai berikut:

Pertama, yang harus diperhatikan oleh sekolah: a) Sekolah harus memberikan penyuluhan pemanfaatan media social kepada guru dan siswa, dan akan lebih baik jika ikut serta menghadirkan orang tua siswa; b) Memberikan panduan cara berkomunikasi serta rambu-rambu yang harus diperhatikan dalam aspek berkomunikasi; c) Menjadikan media sosial sebagai salah satu sarana belajar masa kini; d) Sekolah tidak boleh takut dalam penerapan tata cara bermedia social; e) Sekolah harus memiliki aturan tentang tata cara berkomunikasi di lingkungan sekolah.

Kedua, Untuk siswa dan orang tua siswa: a) Agar berkomunikasi dengan sopan dan santun harus melihat dan memperhatikan kondisi tertentu; b) Orang tua harus terus memberikan pemahaman kepada anak agar tidak salah dalam berkomunikasi; c) Orang tua harus memfasilitasi agar anak tidak merasa tertinggal dalam kemajuan zaman yang ditandai oleh perkembangan teknologi; d) Orang tua dan siswa harus memahami bahwa saat ini penggunaan media sosial dibatasi oleh Undang-undang ITE.

Jadi dari dalam membangun komunikasi sosila media yang humanis benar-benar harus dilakukan dengan cara membangun kerjasama, meningkatkan pemahaman tentang tujuan bersosial media, serta controlling wajib dilakukan oleh lembaga pendidikan (sekolah) dan orang tua dalam rangka merajut dan membangun hubungan yang humanis guna untuk ketercapaian tujuan pendidikan anak didik di sekolah, khususnya di SMPN 9 Tangereang Selatan, Provensi Banten.

\section{KESIMPULAN}

Pengabdian kepada Masyarakat (PkM) dalam rangka Tridharma Perguruan Tinggi, serta salah satu cara dosen mewujudkan manusia cerdas dan humanis dalam berkomunikasi lewat media sosial yang telah dilakukan pada 26 sampai 28 September 2021 kemaren memberikan kesimpulan bahwa:

Pertaman, pentingnya pengetahuan dan sikap bijaksana dalam membangun komunikasi antar sesama oleh setiap lapisan masyarakat, khususnya guru, orang tua siswa dan bahkan siswa sendiri dalam rangka menjaga persatuan dan kesatua yang telah dibubuhkan dalam nilai sila ke 3, yaitu Persatuan Indonesia.

Kedua, pentingnya penyuluhan bagaimana cara membangun komunikasi yang humanis lewat media sosial yang lebih sensitif dibandingkan keomonikasi biasa (tanpa media digital) yang dapat dilakukan oleh lembaga-lembaga pendidikan swatas, negeri dan bahkan lembaga-lembaga lainnya, dalam ikut serta membangun budaya kondusifitas lingkungan komunikasi sosial masyarakat.

Ketiga, pentinga kerjasama antar sekolah, orang tua siswa dan masyarakat serta pemerintah dalam merangkul kepedulian pada regenerasi bangsa (peserta didik) dalam memupuk dan membangun karakter yang baik serta bertanggung jawab dalam setiap aspek. 
Oleh karenanya upaya dalam membangun kemunikasi yang humanis tidak hanya menjadi tanggung jawab sekolah tapi seluruh lapisan masyarakat, lembaga dan lainnya dalam meningkatkan pengetahuan peserta didik, sebab pengetahun yang baik akan berdampak baik pula pada karakter siswa dalam hal apa pun salah satunya adalah dalam berkomunikasi.

\section{DAFTAR PUSTAKA}

Andri, R. M., \& SP, M. P. (2017). Peran dan Fungsi Teknologi Dalam Peningkatan Kualitas Pembelajaran. Jurnal Ilmiah Research Sains,3(1).

Dewantara, J. A., \& Nurgiansah, T. H. (2021a). Peningkatan Keaktifan Belajar Melalui Penerapan Model Picture And Picture Dalam Pembelajaran PPKn di Sekolah Dasar. Jurnal Publikasi Pendidikan, 11(3), 234-241.

Dewantara, J. A., \& Nurgiansah, T. H. (2021b). Strengthening Pancasila Values During the Covid-19 Pandemic. Edukatif: Jurnal Ilmu Pendidikan, 3(4), 2411-2417.

Fitriani, Y. (2017). Analisis pemanfaatan berbagai media sosial sebagai sarana penyebaran informasi bagi masyarakat. Paradigma-Jurnal Komputer dan Informatika, 19(2), 148-152.

Kusno, A. (2015). Pelanggaran Prinsip Kesopanan pada Kasus Delik Penghinaan dan Pencemaran Nama Baik. PROSIDING PRASASTI, 88-93.

Mahadi, U. (2017). Komunikasi humanis. Jurnal Ilmiah Syi'ar,17(1), 11-20.

Nasrullah, Rulli. 2015. Media Sosial; Persfektif Komunikasi, Budaya, dan Sosioteknologi. Bandung: Simbiosa Rekatama Media

Nurgiansah, T. H. (2020). Pelatihan Penulisan Artikel Ilmiah Bagi Mahasiswa PPKn Universitas PGRI Yogyakarta. JNPM: Jurnal Nasional Pengabdian Masyarakat, 1(1), 16-23.

Nurgiansah, T. H. (2021). Pemanfaatan E-Learning Dalam Pembelajaran Pendidikan Kewarganegaraan. JINTECH: Journal of Information Technology, 2(2), 138-146.

Puspita, I. (2017). Efektivitas penggunaan media video animasi dalam proses pembelajaran pendidikan agama islam kelas viii-1 di smp negeri 9 tangerang selatan (Bachelor's thesis, UIN Syarif Hidayatullah Jakarta: Fakultas Ilmu Tarbiyah dan Keguruan, 2017).

Rachman, F., Nurgiansah, T. H., \& Kabatiah, M. (2021). Profilisasi Pendidikan Kewarganegaraan dalam Kurikulum Pendidikan Indonesia. Edukatif: Jurnal Ilmu Pendidikan, 3(5), 2970-2984.

Rosyadi, I. (2018). Pengaruh Multimedia Presentasi Terhadap Kemampuan Menulis Teks Eksplanasi pada Siswa Kelas VIII SMPN 9 Tangerang Selatan (Bachelor's thesis, Jakarta: FITK UIN Syarif Hidayatullah Jakarta).

Setiadi, A. (2016). Pemanfaatan Media Sosial Untuk Efektifitas Komunikasi. Cakrawala - Jurnal Humaniora, 16(2).

Syahputra, A. K., Kurniawan, E., \& Nofriadi, N. (2019). Pemanfaatan Media Sosial Sebagai Media Informasi UPT. Puskesmas Porsea. Jurdimas (Jurnal Pengabdian Kepada Masyarakat) Royal, 2(2), 115-120.

Zainuddin, M., \& Agustang, A. (2019). Kontrol Sosial Orangtua Terhadap Penggunaan Smartphone Pada Remaja (Studi Di Desa Giring-Giring Kecamatan Bontonmpo 
Jurnal Kewarganegaraan

Vol. 5 No. 2 Desember 2021

P-ISSN: 1978-0184 E-ISSN: 2723-2328

Kabupaten Gowa. Jurnal Sosialisasi: Jurnal Hasil Pemikiran, Penelitian dan Pengembangan Keilmuan Sosiologi Pendidikan, 68-73. 